\title{
Study Based on the Micro-Lecture Mode in College English Teaching
}

\author{
Hong-Lei WANG \\ College of Foreign Studies \\ Shandong Technology and Business University, Yantai, China \\ robinhonglei@163.com
}

Keywords: Micro-lecture, application, College English.

\begin{abstract}
The great challenge and influence that micro-lecture brings on traditional college English class cannot be ignored. Based on the analysis of the characteristics of the present college English class in China, this paper explored the application prospect of micro-lecture in college English class, and put forward strategies for the development of college English micro-teaching. The purpose of this study is to improve college English teaching and help to promote the reform of it.
\end{abstract}

\section{Introduction}

It is true that modern life is fully occupied by We-chat, Micro-movie, Micro-novel and Micro-blog. Influenced by the information technology, the traditional way of learning is undergoing changes, from E-learning (Digital Learning) to M-learning (mobile learning) and the present U-learning (ubiquitous learning). Undoubtedly, the traditional face-to-face classroom teaching mode has been challenged as it's becoming increasingly difficult to meet the needs of today's young people in this digital era. For college students fragmented learning and ubiquitous learning have become common and popular. As a new-born thing in this society, micro-lecture is booming in recent years and is regarded as a new mode of teaching and learning. But how to use this new method to improve our college Engish teaching remains a question.

"Micro-lecture" first appeared in the successful use of 60-Second Course by Professor LeRoy A. McGrew from University of Northern Iowa to popularize the knowledge of organic chemistry, and in the One-Minute Lecture (OML) proposed by T.P. Kee from the British Napier University [1]. The concept of micro-lecture was articulated by an independent instructional designer and e-learning consultant David Penrose from San Juan College of the state of New Mexico. David Penrose pioneered the one-minute micro-lecture and called it knowledge burst [2]. He argues that with appropriate assignments and discussion, micro-lecture can achieve the same effect as the traditional class. Today the most influential and popular micro-lecture learning platform is the non-profit Khan Academy which is founded by educator Salman Khan in 2006 with the aim of providing a free, world-class education for anyone, anywhere.

The idea of micro-lecture as an innovative teaching-learning approach was first put forward in 2011 in China, and has aroused extensive discussion ever since. Integrated with Internet, information technology, and other educational and media resources, the micro-lecture teaching-learning mode aims to design and develop a series of online and mobile learning video courses to better illustrate the difficult and questionable points in a course. The interest and discussion surrounding the use of micro-lectures has continued to grow. Micro-lecture is innovative in both its different presentation forms and its specific service object. First of all, micro-lecture is micro video-based, different from the traditional paper-based teaching mode. What's more, its service object is to change the class from teacher-centered to learner-centered; from improving traditional classroom teaching efficiency to promoting the learning and teaching mode reform. As a new product of the information age, micro-lecture will undoubtedly bring opportunities for classroom teaching reform, and it may also be revolutionary to the traditional classroom. 


\section{Characteristics of College English Class in China}

Presently there are mainly three kinds of teaching modes that remain popular in College English teaching. Namely the teacher-centered, the learner-centered and the teaching mode that take the learners as the center and the teacher as the leading role.

Although during the last 20 years college English teaching in China has undergone a long time of challenge and reform, the key point is, no matter which part - the learner, the teacher or both, are taken as the center, the traditional classroom teaching ignores the individual differences that are caused either by different majors or genders. All learners sit in the same classroom at the same time, studying the same textbooks at the same pace by the same approach. As a result, the academic disadvantaged groups that should be fully respected and given more attention to in our teaching are usually ignored and avoided. What's more, college English teaching in China is based on large classes, ignoring individual differences and personalized learning. Student evaluation mainly depends on their examination performance with little attention given to process assessment. The ignorance of the students' initiative and individual differences in English learning leads to the poor teaching effect in college English.

\section{The Application Prospect of Micro-lecture in English Teaching}

Although the new teaching mode of micro-lecture is gaining in popularity, research on micro-lecture is far from enough, and the results are also dispersed. As a matter of fact, the development of micro-lecture is largely due to various micro-lecture contests and events held in recent few years. Take the most influential National Universities Micro-Teaching Competition for example, a large number of outstanding foreign language micro-lecture works emerged. Actually, foreign language micro-lectures outweigh lectures of other fields not only in quantity but also in quality. In the first National Universities Micro-Teaching Competition, entries that received the largest number of online reviews falled into the category of language and culture. It reflects the great interest and high attention of micro-lecture observers to language micro-lectures, and also reflects the public's potential demand for language micro-lectures.Various contests show that college English, as a public course, is just right for the application of micro-lectures in its teaching and the entries have received very positive feedbacks. The large number of foreign language micro-lecture works emerged in all these contests provides valuable resources and reference for the production, construction and development of micro-teaching in College English. It an be safely concluded that the micro-lecture teaching mode has broad prospects in English teaching.

To begin with, micro-lecture can be a very helpful teaching aid in traditional language teaching. Micro-lectures, presenting knowledge and information in the forms of micro video, micro animation and micro exchange, aim to impart the important and difficult points to the learners through very brief explanation. So it serves as a good choice for fragmentation learning. At the same time, micro-lectures make it easier for the classroom to take diversified and enriched teaching forms.

Secondly, with the characteristics of being vivid and novel, theme prominent, short and interactive, micro-lectures appeals more to the students. In contrast, the traditional classroom, whether it is indoctrination or discussion, inevitably falls into complicated and boring grammar and vocabulary explanation. Micro-lectures can create a pleasant atmosphere and help to stimulate learning enthusiasm, which in turn improves learning effect.

Next, being mobile and easy to share, micro-lecture makes it more convenient for self-study. Acquisition of a language shouldn't be limited in classroom teaching. Micro-lectures provide more possibilities for learning English, making it easy for the students to study either in fixed locations like the classroom, library, or by watching online or downloading from the Internet for later independent learning. Besides, it is more convenient for the learners to exchange and discuss about their studies on the online platform.

Finally, micro-teaching is more interactive. The opening and sharing of micro-lectures not only means sharing micro videos, but also the sharing of a micro platform for discussion and interaction. It 
is easier for the students to upload questions onto the micro platform, giving feedbacks to the teacher; the teacher can thus answer the questions, solve the problems and then modify and perfect their work. In this way, interactive teaching is truly realized [3].

\section{Strategies for Developing College English Micro-teaching}

Driven by a number of micro-teaching contests and partly due to the popularity of MOOC and flipped classroom, micro-teaching has gradually become a focus in the field of college English. On the other hand, with the development of network technology, students are no longer satisfied with the traditional classroom learning. More and more college students begin intentionally or unintentionally to search for some non-traditional learning resources outside the classroom (online learning platform) to try a diversified, flexible and free way of learning English. These attempts are still in the stage of ignorance and blindness, and it is imperative for teachers to guide and regulate them. Once teachers give timely and correct guidance, students will be more purposeful and targeted in learning micro-lectures, and their learning efficiency, autonomy and interest will be greatly improved. Therefore, the following measures can be taken in the development college English teaching and English micro-teaching in the future.

\section{Exploration of College English Micro-Teaching Mode}

Although the development of micro-lectures is booming, few colleges and universities carry out large-scale college English micro-teaching mode. Compared with other disciplines, there is still a long way to go for the construction of micro-courses, especially the construction of college English micro-courses. Colleges and universities are faced with the urgent need to build micro courses. Based on the successful practice of network and multimedia teaching model, colleges and universities should take full advantage of their software and hardware resources and try to further deepen and promote the reform of College English teaching.

\section{Establishing a Micro-Learning Platform}

Micro-teaching has become a focus in the field of college English. A micro-course, however, is not a simple collection of scattered and disorganized micro videos. To make micro-lectures handy and convenient for fragment learning, micro-teaching must be incorporated into the whole college English curriculum system, supported by a complete curriculum structure, and an efficient micro-course platform for interaction.

The existing college English micro-lecture resources are scattered and messy, and there is no continuity and progression. Self-built micro-course platform should make up for these defects and realize the systematization of College English micro-teaching, so as to ensure the continuity and repeatability of learning. That is, it can meet the students' need of learning the whole course systematically and also help them construct their own knowledge system. By creating such a platform, we actually provide the students with an excellent learning community which makes it convenient for students to carry out inquiry learning so as to help them learn more effectively at their own pace.

\section{Training of Teachers}

In the era of rapid development of information technology, college teachers must study information technology knowledge and master information skills in order to properly use them in teaching. Applying information technology to classroom teaching is a trend, and also a direction of reform in classroom teaching. The production and development of micro-lectures need advanced information and network technologies. First of all, it is necessary to popularize the micro-teaching concept. Judging from various micro-lecture contests, we can safely conclude that micro-teaching is fit for foreign language courses. What is involved in a college English class is numerous and jumbled, covering from spoken English, grammar, culture to writing and translation. To produce a series of micro-lectures which make independent learning easy may greatly alleviate the pressure of the classroom and meet the requirements of different levels of students. Then we should provide technical guidance and proper training of producing micro-video for teachers. In reality, the production of a 
micro-lecture must go through various steps, including selection of a subject, design, development, testing, and the like. So it is important to make policies that encourage college English teachers to receive micro-teaching training, to carry out the development, application and research of micro-teaching in various ways. With the improvement of the teacher's ability of making micro-lecture videos, they will also receive further professional advancement so as to establish a leading team for the production of College English micro-lectures in the near future.

\section{Incorporated into MOOC and Flipped Classroom}

Due to its typical feature of being easily used, reused and shared, Micro-lecture plays a key role in MOOC and flipped classroom teaching. To incorporate micro-lecture into MOOC and flipped classroom teaching is a direction of college English teaching reform.

MOOC (massive open online course) aims at unlimited participation and open access via the web. Traditional course materials of MOOCs are filmed lectures, readings, and problem sets. It is in this sense a micro-teaching way of education with video resources. It provides the students with systematic learning by subjects through their fragment learning anytime and anywhere. Therefore, the construction of college English micro-lectures should be guided by an overall planning and take large-scale open learning as its goal. In addition, micro-lecture resource should highlight its convenience for interactive communication, because many MOOCs provide interactive user forums to support community interactions among students, and teachers. Interactive communication is a major feature of MOOC.

Flipped classroom, an instructional strategy and a type of blended learning that reverses the traditional learning style by delivering instructional content, often online, outside of the classroom teaching, has become a popular teaching mode in college English in recent years. The flipped classroom aims to shift instruction to a learner-centered model in which class time explores topics in greater depth, while educational techniques and resources such as online videos are used to deliver content outside of the classroom. In a flipped classroom, students watch online lectures, collaborate in online discussions, or carry out research at home and engage in concepts in the classroom with the guidance of a mentor. It seems that providing proper and high quality short videos seems to the key of success for flipped classrooms. With the rise of the flipped classroom teaching mode, micro-lecture is applied more and more frequently in the teaching. Therefore, efficient micro-lectures can serve as a very important and even indispensable part of a flipped classroom.

\section{Conclusion}

With the development of modern information and educational technology, micro-lecture, the form of which is short and terse, novel and lively, has won both the teachers and learners' hearts. It enables the learners, the Digital Natives who are born and living in a world of internet to make full use of their spare time to learn at anytime and anywhere. On the other hand, the majority of the college English teachers, the so called Digital Immigrants who often feel powerless in the face of massive digital information, the rapid development of technology and digital products, must update their concepts about teaching, apply information technology to their teaching and actively explore the teaching law in the information age.

One thing that should be avoided in micro-lecture development, however, is the problem of valuing construction and neglecting application. Due to the promotion of many competitions, a large number of college English micro-lectures emerged, but many works were not made for the purpose of application but for competition, which is not only a waste of resources but may lead the construction of micro-lectures in the wrong direction. Since the learner's interest should always be out in the first place, the construction of micro-lectures should be based on the benefit of English teaching and learning, focusing on its reusability to produce a series of systematic micro-courses. 


\section{References}

[1] LeRoy A. McGrew, "A 60-Second Course in Organic Chemistry,” [J]. Journal of Chemistry Education, 1993, (70), pp. 543-544.

[2] Huang J.J.,Guo S.Q., "On the Design and Development of Micro Curriculum," [J]. Modern Educational Technology, 2013, (5), pp. 31-35.

[3] Chang Z.H., "Micro-lecture: a New Type of Learning Resources," [J]. China Educational Technology \& Equipment, 2013, (20), pp. 50-51. 